\title{
EL PROGRAMA BRACERO (1942-1964). UN BALANCE CRÍTICO
}

\author{
JORGE DURAND
}

RESUMEN: El Programa Bracero (1942-1964) es quizá el ejemplo más relevante que existe, por su dimensión y duración, de los Programas de Trabajadores Temporales a nivel mundial. Sin embargo, ha sido ampliamente criticado y muy poco estudiado. En este artículo se utilizan materiales de la época para reevaluar los pros y los contras del Programa y tener elementos para replantear lo que podría ser un futuro programa de trabajadores temporales entre México y Estados Unidos.

PALABRAS ClaVe: Programa Bracero; Migración; Trabajadores Temporales; México; Estados Unidos.

ABSTRACT: For its dimension and duration, the Bracero Program (1942-1964) is the most relevant example of Temporary Workers Program existent until now. However, the program has been widely criticized and very little studied. This article uses materials of that period to re-evaluate the Program pros and cons in order to re-think what could be the future of a temporary worker program between Mexico and the United States. KEYWORDS: Bracero Program; Migration; Temporary Workers; Mexico; United States.

\section{INTRODUCCIÓN}

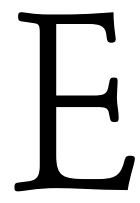

n el contexto de la discusión sobre la pertinencia de un acuerdo bilateral para establecer un nuevo programa de trabajadores migrantes, resulta indispensable volver a la experiencia pasada, al Programa Bracero, que si bien es un tema añejo, no por eso deja de contener errores corregibles y sabias enseñanzas. A fin de cuentas, el Programa Bracero, ha sido el esfuerzo más consistente, de mayor magnitud y de mayor alcance del que podamos echar mano para pensar y repensar sobre el tema y el problema de los contratos temporales de trabajadores migrantes. 
Los antecedentes inmediatos del Programa Bracero fueron el sistema de contratación conocido como el «enganche» y las deportaciones masivas de las décadas del veinte y treinta. Ambas modalidades de contratación y manejo de la mano de obra migrante fueron nefastas. El sistema de enganche, como negocio privado de las casas de contratación, fue un modelo de explotación extremo que dejaba en manos de particulares la contratación, el traslado, el salario, el control interno de los campamentos y las cargas de trabajo. Las consecuencias de este sistema fueron los contratos leoninos, el endeudamiento perpetuo, las condiciones miserables de vida y trabajo, el trabajo infantil, las policías privadas y las casas de contratación (Durand, 1993, 1994).

Por su parte, las deportaciones masivas (1921, 1929-33 y 1939), fueron una respuesta selectiva en tiempos de crisis y contracción del mercado de trabajo estadounidense. Sólo y únicamente los trabajadores mexicanos, entre decenas de otros grupos de inmigrantes, fueron deportados de manera masiva y en repetidas ocasiones. Con ninguna otra comunidad de inmigrantes se aplicó una política semejante. Más aún, se diseñó un programa de deportación selectivo a nivel regional, en el que se procuraba deportar a los mexicanos que trabajaban en la industria, especialmente en los estados del norte y reorientar el flujo migratorio hacia el suroeste y las actividades agrícolas (Taylor, 1930; McBride, 1963; Carreras, 1974). La deportación masiva puso en evidencia, por una parte, que es la demanda la que impone el ritmo migratorio y por otra, que cuando no hay trabajo, el stock y el flujo disminuyen de manera drástica, sea por la vía de la deportación oficial, el retorno voluntario o las dificultades para el cruce fronterizo. Dados los antecedentes de las deportaciones masivas y el predominio del sistema de enganche, es de suponer que el Programa Bracero fue un cambio significativo.

\section{LOS PRIMEROS CONVENIOS DE BRACEROS}

Una evaluación del Programa Bracero obliga, sin embargo, a remontarse hacia antecedentes más lejanos. El primer acuerdo bilateral del que se tenga noticia data de casi un siglo atrás. En 1909 el Presidente Porfirio Díaz, en el último año de su mandato y el Presidente de Estados Unidos William H. Taff, en el primero de su administración, firmaron un convenio para la exportación de 1,000 trabajadores que deberían ir a laborar a los campos de betabel, una industria considerada como prioritaria para el gobierno americano, dada la ausencia de climas adecuados para la producción de caña de azúcar. Según Vargas y Campos (1964) estos primeros braceros se dirigieron al sur de California; mientras que Daniel Casarrubias (1956) afirma que fueron contratados para trabajar en los campos de betabel de Colorado y Nebraska y que los trabajadores fueron reclutados en poblaciones del norte de México. 
Un año después, Francisco Indalecio Madero en vez de propugnar la contratación de braceros como Don Porfirio, llamaba la atención en su obra La sucesión presidencial, (1911) sobre las pésimas condiciones de vida y trabajo de los migrantes: «La situación del obrero mexicano es tan precaria que a pesar de las humillaciones que sufren allende el Río Bravo, anualmente emigran para la vecina República millares de nuestros compatriotas, y la verdad es que su suerte es por allá menos triste que en su tierra natal».

Durante la época revolucionaria no fueron necesarios los convenios braceros, no había con quién firmarlos y más aún, no eran necesarios. Decenas de personas cruzaban todos los días el Río Bravo, se quedaban unos días en Fort Bliss como refugiados y luego buscaban la manera de «engancharse» para ir a trabajar en el ferrocarril, las minas, fundidoras o campos de cultivo (Durand y Arias, 2005). No obstante, en 1917 cambió totalmente el escenario político, económico y laboral de Estados Unidos. El país vecino entró de lleno en la Primera Guerra Mundial y cientos de miles de varones en edad laboral abandonaron sus puestos de trabajo para ir a los frentes de guerra.

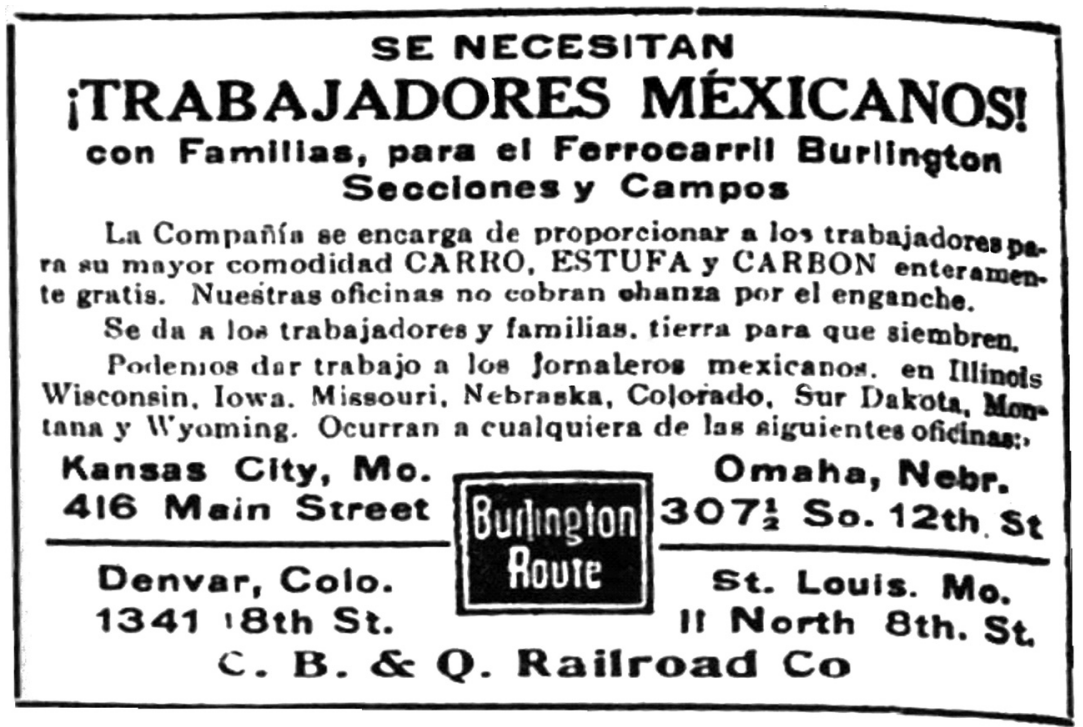

El Cosmopolita, semanario de Kansas City, 1917.

El 5 de febrero de 1917 se promulgó en Estados Unidos la ley migratoria conocida como Burnett que condicionaba el ingreso de los inmigrantes al pago de \$8 dólares y a que los mayores de 16 años demostraran que sabían leer y escribir. Esta ley, como muchas otras de carácter general, solucionaba problemas en un lado y los creaba en otro. En principio, se trataba de detener el flujo de inmigrantes analfabetas que provenían del Este y el Sur de Europa y que huían de la Primera Guerra Mundial, pero esto afectó a los trabajadores migrantes mexicanos, que por lo general no podían cubrir el requisito de alfabetización y menos aún pagar una cuota de \$8 dólares. El resultado fue la deportación sistemática de trabajadores 
mexicanos y mayores dificultades para cruzar la frontera de manera legal (Cardoso, 1980; Alanís, 1999). Esta ley apareció en una pésima coyuntura, justo antes de que Estados Unidos ingresara a la Primera Guerra Mundial, el 2 de abril de 1917, y que se manifestara, por una parte escasez de mano de obra y por otra una mayor demanda de la misma.

A los tres meses de promulgada la ley, y al mes siguiente de que se declarara la guerra, en mayo de 1917, se promulgó una excepción para aquellos que fueran trabajadores temporales y que se dedicaran exclusivamente al trabajo agrícola, es decir, los mexicanos. De este modo las leyes, disposiciones y excepciones fueron conformando un flujo de inmigrantes mexicanos que se caracteriza por ser una mano de obra temporal y por dedicarse prioritariamente a la agricultura. Este modelo sería perfeccionado y reajustado posteriormente durante el Programa Bracero.

Como quiera, las enmiendas legales tardaron meses en aplicarse y se dificultaba la importación masiva de mano de obra, ya no sólo para la agricultura, sino también para la minería, los ferrocarriles y la industria. La guerra desplazaba a cientos de miles de personas que tenían que integrarse a las distintas ramas de las fuerzas armadas, pero al mismo tiempo se requería de más alimento, más minerales, más productos, más armamento. De ahí que los empleadores americanos presionaran al gobierno para establecer programas de reclutamiento de mano de obra mexicana. Las necesidades eran tan perentorias que los enganchadores preferían a los migrantes que tuvieran familia, ya que todo el grupo familiar podía ser integrado a las labores del campo. Pero, no sólo los empleadores tenían interés en la migración mexicana, también los reclutadores del ejército, que promovían y en su caso exigían a los trabajadores a que se naturalizaran. En 1918 ya habían sido enrolados y enviados al frente de guerra cerca de 60,000 mexicanos, tanto de origen como de nacimiento, el grupo más numeroso de extranjeros radicado en Estados Unidos que participó en la guerra (Alanís, 1999).

El reclutamiento, forzado o no, por parte de las fuerzas armadas y las presiones para que los mexicanos se naturalizaran a cambio de obtener un trabajo fueron tales, que generaron un éxodo masivo de retorno a México. Los mexicanos ya tenían experiencia al respecto, habían huido de la revolución convirtiéndose en emigrantes y regresaban a México para escapar de la leva que los quería incorporar a la Primera Guerra Mundial. En ese tiempo naturalizarse significaba convertirse en carne de cañón. Según Alanís (1999), cerca de 70,000 mexicanos regresaron entre 1917 y 1918. Algunos huían por miedo a la leva, otros regresaban a sus lugares de origen una vez concluido el enfrentamiento armado en México.

Como era de esperarse el reclutamiento de trabajadores mexicanos en la frontera generó una serie de reacciones en contra por parte de la nueva clase política mexicana que trataba de desalentar el proceso. De hecho allí se empezó a gestar la política emigratoria de la época que era claramente de carácter disuasivo y que va perdurar hasta fin de la década del treinta (Durand, 2005). Como quiera 
que impedir el flujo de salida era poco práctico, si no imposible, las autoridades federales «hicieron todos los esfuerzos para que sus compatriotas sufrieran lo menos posible durante su estadía en el extranjero» (Alanís, 1999: 73).

Hubo muchas negociaciones durante aquellos años, sobre todo entre los cónsules de ambos países, los gobernadores fronterizos y los alcaldes de ciudades vecinas. Pero muchas veces no se ponían de acuerdo entre ellos mismos, ni con el gobierno federal. Los gobernadores desalentaban la emigración, ya que requerían de brazos para la reconstrucción del país después de la revolución, mientras que los cónsules se sentían presionados por diferentes agentes y funcionarios del gobierno americano, que demandaban facilidades para que llegaran braceros.

Alanís (1999), quien estudió a fondo la época, argumenta que para hablar de un «Programa Bracero» no se requiere necesariamente de un acuerdo entre los poderes ejecutivos de ambos países y que en la práctica se dio un programa de migración temporal, concertada por medio de los cónsules y las autoridades fronterizas. No obstante, las cifras que proporciona el mismo autor generan dudas al respecto. Según esto, regresaron entre 1917 y 1918 cerca de 70 mil mexicanos y fueron contratados en esos años unos 72,000 braceros. Si tomamos estas cifras como ciertas, lo único que parece haber pasado es que regresó a Estados Unidos un contingente semejante al que había salido huyendo.

En referencia a esta época Casarrubias (1956) comenta que «Se ignora el número de compatriotas que hayan ido a prestar sus servicios en calidad de braceros, ya que no medió acuerdo formal alguno, ni se llevó estadística de ninguna especie». Por su parte, Vargas y Campos (1964) señala que «los Estados Unidos se vieron precisados a dictar medidas legislativas que facilitaran la entrada al país de trabajadores mexicanos, ya que sus campos habían quedado abandonados al aumentar el efectivo de sus tropas; nuestros trabajadores respondieron en forma favorable al llamado que se les hacía dirigiéndose en gran número a trabajar a los campos estadounidenses». La misma autora señala que en 1917 salieron 17,869 emigrantes legales y 812 ilegales, de acuerdo con registros americanos y que en 1918, se incrementó el número de legales a 18,524, pero sobre todo, creció el de ilegales que alcanzó la cifra de 25,515.

Desde nuestro punto de vista, faltan tres elementos fundamentales para hablar propiamente de un Programa Bracero. Primero que exista un «convenio» o un «acuerdo» bilateral entre los gobiernos de ambos países. En segundo término, que el «programa» tenga cierta continuidad y que no sea una respuesta coyuntural. En todo caso el acuerdo de Díaz y Taff, de 1909, bien podría ser el «primer» convenio bracero. En tercer lugar, deben existir ciertas condiciones para que se de un acuerdo bilateral, asunto bastante difícil de lograr en 1917. En esos precisos momentos el Congreso Constituyente legislaba sobre principios laborales básicos y señalaba una serie de limitaciones para los contratos realizados por extranjeros y la salida de nacionales. Por otra parte, el gobierno Carrancista tenía múltiples problemas internos por resolver y enfrentaba una situación política bastante inestable. 
Los cónsules, presidentes municipales y gobernadores respondían de manera diferente a las presiones de los norteamericanos sobre las solicitudes de mano de obra. El estudio de Alanís (1999) pone en evidencia precisamente estas contradicciones y cómo cada autoridad local fijaba condiciones a su buen saber y entender. Hubo pláticas y acuerdos consulares, pero nunca se dio una negociación bilateral entre ambos gobiernos y menos aún se firmó un convenio. En este periodo son las guerras, la Revolución Mexicana y la Primera Guerra Mundial, las que, por razones diferentes, le dieron un empuje tremendo a la migración entre México y Estados Unidos. Los factores de expulsión y atracción se conjuntaron en esos años para darle un impulso definitivo a la migración mexicana.

\section{UNA REEVALUACIÓN DEL PROGRAMA BRACERO}

Existen numerosos estudios, comentarios, evaluaciones, críticas y juicios sobre el Programa Bracero. Algunos fueron realizados durante el funcionamiento del Programa mismo, como el libro de Ernesto Galarza (1964) y los que se reseñan en antología elaborada por Durand (2007). Según Carey McWilliams (1954), una buena parte de los logros obtenidos por la parte mexicana, durante la primera fase de negociaciones del Programa Bracero, se debe precisamente a la intervención y asesoría de dos académicos de la época: Manuel Gamio y Ernesto Galarza. Obras posteriores, profundizaron en temas paralelos, como la de Julian Samora (1971) que se aboca al estudio de los espaldas mojadas; la de Richard Craig (1971) que estudia la conexión entre los grupos de poder económico y las políticas migratorias, o la de Kity Calavita (1992) que profundiza en los aspectos legales del tema.

Como quiera, toda evaluación requiere plantear y discutir los temas en blanco y negro, aunque se corran ciertos riesgos y se simplifiquen argumentos. Para muchos autores, incluso críticos como Carey McWilliams y Galarza, el Programa Bracero tuvo notables ventajas, sobre todo si se le compara con la situación anterior del enganche y el panorama desolador de los espaldas mojadas, que no gozaban de ninguna protección, ni siquiera en el papel. En efecto, esta sería la primera cualidad del Programa Bracero, haber roto de manera definitiva con el modelo anterior.

1. Un cambio radical del patrón migratorio. La primera virtud del Programa Bracero fue acabar con el sistema de enganche. La contratación dejó de ser un negocio particular y pasó a depender de programas oficiales de carácter bilateral. Sólo en un par de ocasiones se optó por la contratación unilateral, pero incluso en este caso fue controlada oficialmente por el gobierno americano (García Tellez, 1955; de Alba, 1954; Casarrubias, 1956). El Programa Bracero inaugura un nuevo periodo en la historia de la migración México-Estados Unidos, transforma radicalmente el patrón migratorio que deja de ser familiar, de larga estancia y dudosa situación legal, para convertirse en un proceso legal, masculino, de origen rural y orientado hacia el trabajo agrícola. 
2. El acuerdo bilateral reconoce la existencia de un mercado de trabajo binacional. La segunda virtud del acuerdo fue el reconocimiento explícito, por parte de Estados Unidos, de la existencia de un mercado de trabajo binacional. No había que ir a otros países o continentes a buscar trabajadores, desde hacía décadas se daba un flujo de trabajadores entre México y Estados Unidos. A diferencia de la mayoría de las leyes migratorias norteamericanas que son de aplicación general, el Programa Bracero fue un acuerdo bilateral, promovido originalmente por Estados Unidos y sostenido por el interés mutuo de ambas partes. El Programa se dio en un contexto de guerra, pero fue tan exitoso y beneficioso para los agricultores norteamericanos que se prolongó veinte años más.

México siempre ha propugnado por una situación de excepción en cuanto a las políticas migratorias norteamericanas, que suelen ser de carácter general. Poco se ha logrado a nivel bilateral, una vez concluido el Programa Bracero, a pesar de que se esgrimen razones históricas y de vecindad. Pero de facto los mexicanos y la comunidad de origen mexicano en Estados Unidos han ido ganando posiciones y espacios en el medio económico, político y cultural.

3. La migración temporal, como tipo ideal. La tercera ventaja del Programa Bracero, fue su carácter temporal. Los trabajadores iban y regresaban. Este punto es fundamental, porque es un elemento de coincidencia plena de los dos gobiernos involucrados. México y Estados Unidos, incluso en la actualidad, están de acuerdo en que la migración legal, de tipo temporal, es una de las mejores opciones. El dicho aquel de que «no hay nada más definitivo que un trabajador temporal» (Martin y Teitelbaum, 2002), se ajusta a la problemática europea, no al caso mexicano, como afirman los autores citados. Tampoco es el caso de la experiencia del convenio entre México y Canadá para trabajadores temporales, donde el retorno es un hecho generalizado. Más aún, la experiencia en conjunto del proceso migratorio entre México y Estados Unidos, tanto de trabajadores legales como indocumentados, parece indicar una clara preferencia por la migración temporal. Según los datos del Mexican Migration Project, correspondientes a todas las épocas, más el 56\% de los migrantes, de todas las épocas, sólo fueron en una ocasión a trabajar a Estados Unidos y un 16\% adicional solo realizó dos viajes (Mexican Migration Project, 2006, 107 comunidades).

4. Un programa de larga duración. En cuarto lugar, hay que señalar que el Programa Bracero funcionó a lo largo de 22 años. Tuvo sus altas y sus bajas, pero no se puede decir que un convenio bilateral que funcionó durante dos décadas y movilizó a cerca de cinco millones de trabajadores haya sido un fracaso. La duración del Programa es el mejor argumento en un ejercicio de evaluación. Obviamente hubo un sinnúmero de problemas, pero es algo normal en un acuerdo de esta naturaleza, con esta duración y de esta magnitud.

Los encargados de la política migratoria de la época tuvieron los recursos y la capacidad suficiente para corregir desviaciones serias y superar obstáculos que parecían prácticamente infranqueables. El Programa funcionó, a pesar de que du- 
rante varios años México aplicó un veto explícito al Estado de Texas, por prácticas de discriminación. El veto de poco servía, porque los tejanos seguían contratando mojados, pero hubo avances notables en contra del racismo y la discriminación. No deja de ser sorprendente la capacidad de negociación que tuvo el gobierno mexicano en aquella época, no en vano se acababa de realizar la expropiación petrolera y se había profundizado la reforma agraria, afectando propiedades norteamericanas.

Cuando ambas partes no pudieron llegar a un acuerdo en 1954, y se canceló el Programa de manera unilateral, México tuvo que aceptar que era improcedente la pretensión de impedir por la fuerza la salida de sus ciudadanos y Estados Unidos tuvo que aceptar que no era conveniente llevar un programa bracero unilateral. Esta operación, conocida como el secado de mojados, no era otra cosa que una amnistía realizada al vapor y una medida de presión coyuntural que no pudo durar mucho tiempo. Incluso después de la operación wetback, en la que se deportaron a cerca de un millón de indocumentados, el gobierno mexicano supo recomponer las relaciones y renegociar el Programa. Obviamente, con todas estas presiones México y los trabajadores iban perdiendo posiciones, pero el convenio se prorrogó por diez años más.

5. Un programa acotado y flexible. En quinto lugar, valdría la pena recordar que se trató de un programa acotado. Pretendía solucionar el problema de la escasez de mano de obra en un campo específico del mercado de trabajo: la agricultura. Pero, al mismo tiempo, fue un programa suficientemente flexible como para implementar el Programa Ferroviario de corta duración (1943-1945), porque el momento y las necesidades de mano de obra así lo requerían. Incluso se llevó a cabo un programa similar para el caso del trabajo en las minas (Driscoll, 1985; Jones, 1946). Es decir, fue un programa limitado, pero a la vez, pudo ser utilizado de manera creativa de acuerdo con las necesidades del momento. El Programa ferroviario llegó a contratar a 130,000 trabajadores entre 1943 y 1946. Como quiera, esta flexibilidad también se manifestó a nivel temporal por la extensión del programa a lo largo de 22 años y no únicamente a los años de la guerra.

Este acotamiento tiene su contraparte en los trabajadores y su extracción social, lo que tiene obviamente virtudes y defectos. Pero hay que reconocer que los «beneficiarios» del programa eran trabajadores del campo, que a fin de cuentas eran los más necesitados del país. Ellos pudieron tener acceso a mayores recursos económicos, recursos que nunca hubieran podido lograr trabajando en México.

6. Mejoran las condiciones laborales y salariales. El Programa Bracero constituyó un avance sustancial en cuanto a las condiciones de vida y trabajo de los trabajadores migrantes. Se llegaron a formular acuerdos y disposiciones para garantizar condiciones mínimas de legalidad, contratación, estabilidad laboral, seguridad social, vivienda, transporte y salario mínimo. La experiencia del Programa Bracero fue retomada posteriormente en conferencias y acuerdos mundiales sobre los derechos de los trabajadores migrantes. 
Como se sabe, la realidad cotidiana no fue la panacea. El trabajo migrante es, por definición, el más duro, el más desgastante y el peor remunerado de la escala laboral. Las condiciones de la vivienda, en su mayoría barracones, eran bastante precarias y en ocasiones las personas vivían en casas de campaña. Como quiera los braceros no tenían que pagar renta, lo cual les permitía ahorrar en ese rubro del gasto cotidiano que siempre se lleva una buena parte del salario. Hoy en día, en el condado de San Diego, el más rico de Estados Unidos, hay trabajadores mexicanos que viven en cuevas y jacales en los cerros aledaños. Las condiciones parecen no haber cambiado, o mejor dicho, parecen estar peor. Durante el tiempo de los braceros, por lo menos, existía la posibilidad de llegar a acuerdos, gestionar cambios, recibir quejas y buscar soluciones.

7. Una maquinaria burocrática eficiente. El Programa demostró en repetidas ocasiones ser una maquinaria eficiente. Llegó a movilizar entre 1954 y 1960 a un promedio de 350 mil trabajadores anualmente. Es más, en julio de 1954, de manera sorpresiva y para boicotear al Programa, los empleadores del estado de Texas, acostumbrados a contratar mojados, solicitaron 60,000 braceros que debían ser contratados en 15 días. Y la burocracia de ambos países se puso en marcha. E1 centro de contratación de Monterrey llegó a contratar a 4,000 braceros diarios. Lo que finalmente obligó a los tejanos a incorporarse al sistema bracero (Salinas, 1955: 21).

Obviamente, esta apreciación tiene su contraparte. Pero las burocracias de ambos países habían logrado trabajar de manera conjunta, los canales de comunicación estaban abiertos de manera permanente y, finalmente, se fueron formando especialistas en el manejo de poblaciones móviles.

8. Un programa costeable. Finalmente, el programa suponía una serie de gastos, para ambos gobiernos y para los empleadores. Pero a pesar de las quejas y la resistencia a conceder ciertas prestaciones, ésto no significó la quiebra de ninguna empresa, ni una escalada de salarios y precios de los productos agrícolas. Distintos reportes de la época señalan que con el tiempo el Programa fue superando dificultades y los empleadores empezaron a valorar sus ventajas y a cooperar decididamente para su buen funcionamiento (Jones, 1946; Fernández del Campo, 1946; De Alba, 1954; Salinas, 1955; García Téllez, 1955). A fin de cuentas, los costos económicos, sociales y políticos que acarrea la ausencia de un programa bilateral, son mucho mayores.

Las consecuencias negativas del Programa Bracero fueron también numerosas, aunque no todas se le pueden achacar al Programa mismo.

1. La oferta mayor que la demanda oficial de braceros. Una de las consecuencias negativas del Programa Bracero fue el movimiento paralelo de trabajadores indocumentados, que llegó a tener dimensiones semejantes. Se calcula que en los 22 años del Programa Bracero ingresaron cerca de 5 millones de indocumentados a Estados Unidos. Obviamente, el Programa no satisfacía plenamente la demanda, pero la solución no era fácil para ninguno de los dos países. Para México era com- 
plicado, políticamente hablando, duplicar en número de braceros y para Estados Unidos también. En realidad ambos gobiernos eran plenamente conscientes del problema, pero poco podían hacer al respecto. La única medida de excepción fue la deportación masiva con la Operación Wetback, que tuvo como consecuencia un incremento notable en las contrataciones en los años siguientes.

Ante esta problemática, ambas partes se echaban la culpa: se afirmaba que México debía hacer algo para controlar la salida de indocumentados y, como contraparte, se le señalaba al gobierno de Estados Unidos que se debía castigar a los que emplearan indocumentados. Según Calavita (1992) la política migratoria de Estados Unidos siempre alentó, sea de manera formal o informal, el tráfico ilegal. El acuerdo de 1949 decía que los trabajadores indocumentados que se encontraran en Estados Unidos debían tener "preferencia» y ser regularizados según el sistema de «secado de mojados». La patrulla fronteriza llevaba a los migrantes indocumentados a la frontera, estos pisaban simbólicamente el lado mexicano y luego volvían y eran admitidos legalmente (Galarza, 1964; Calavita, 1992). Posteriormente en 1948, ante la negativa mexicana de enviar braceros a Texas porque no se aceptaban las condiciones convenidas, la frontera se abrió por cinco días en el mes de octubre y dejó pasar a todos los que quisieran trabajar.

En 1952 se promulgó la ley McCarran-Walter Act, que consideraba como ilegal acoger, transportar o encubrir a personas que hubieren entrado sin documentos "harbor, trasnport, or conceal ilegal entrants, or directly or indirectly induce their entry into the US». Sin embargo, la enmienda llamada "Texas Proviso» lograda por presiones de los agricultores excluía a los empleadores (Calavita, 1992). Esta enmienda estuvo activa hasta 1986, cuando la ley IRCA volvió nuevamente a condenar, en el papel, a los empleadores que contrataran indocumentados. Nunca ha habido realmente, de parte de Estados Unidos, voluntad política para castigar a los empleadores, lo que en los hechos fomenta y facilita la migración indocumentada.

2. Un convenio bilateral o un acuerdo obrero patronal. En segundo término habría que señalar la beligerancia de las partes y el carácter de fondo del convenio, que era de orden obrero-patronal. Cada año se negociaba una especie de «convenio colectivo de trabajo» y las partes lógicamente no se ponían de acuerdo. México amagaba con la «huelga», es decir, se negaba a enviar trabajadores en esas condiciones y Estados Unidos contrataba a los trabajadores de manera unilateral o legalizaba a indocumentados y, de este modo, los utilizaba como «esquiroles». Estas tensiones contrastan con la facilidad con la que se llegó a un convenio en 1942 cuando se inició el programa. El jaloneo de ambas partes y la falta de acuerdos razonables a mediano y largo plazo fueron, sin duda, un problema recurrente en la negociación anual bilateral.

No obstante, es necesario destacar que se pueden distinguir cuatro etapas en este proceso. Durante el primero y segundo años (1942-1943) estuvo a cargo del Programa la Farm Security Administration, quien en años anteriores se había destacado por su apoyo incondicional a los trabajadores agrícolas y por propugnar una 
serie de mejoras, especialmente en la vivienda y los campamentos. Pero en julio de 1943, la administración pasó a manos de la War Food Administration (McWillians, 1949) y posteriormente a la Oficina del Trabajo (Jones, 1946). Finalmente, en 1954, con la renegociación del convenio, el gobierno de los Estados Unidos dejó de ser el contratante y les pasó la estafeta a los particulares, que por medio de asociaciones debían solicitar los contingentes de braceros. Según Casarrubias (1956), este último cambio fue radical y dejó en peor situación a los trabajadores que se tenían que arreglar directamente con los patrones y el gobierno solamente supervisaba.

3. Gastos, trámites y burocracia excesiva. En tercer lugar se argumentó que el funcionamiento del Programa requería de una burocracia excesiva en ambos lados de la frontera. Los empleadores se quejaban de tantos gastos y papeleo, cuando tradicionalmente llegaba la mano de obra a su destino, sin ningún costo para ellos y con el único problema de que eran indocumentados (De Alba, 1954). Cuando empezaba el programa, el año de 1945, se requirieron en Estados Unidos de 2,400 personas para llevar a cabo las tareas normales del Programa y se gastaron varias decenas de millones de dólares (Jones, 1946).

En México, la administración del Programa, además de gastos, generó corrupción y tráfico de influencias (Madrazo, 1945; Salinas, 1955; Martínez, 1948). Problema que no pudo resolverse y que sigue siendo la amenaza principal de todo programa que llegue a implementarse en el futuro. Los costos de la corrupción, obviamente, tuvieron que pagarlos los migrantes en forma de mordidas, donaciones o favores.

Un problema adicional fue la medida paternalista que el gobierno mexicano impuso a los braceros, al obligarlos a realizar un ahorro del 10\% de sus salarios en bancos norteamericanos Wells Fargo y Union Trust Co., de San Francisco, que a su vez serían depositados en el Banco Nacional de Crédito Agrícola de México. Este acuerdo funcionó de 1943 a 1949. Según Jones, en 1943 se recaudaron 11.6 millones de dólares y se devolvieron 2.6 millones. En 1944 se habían recaudado 18.4 millones de dólares, en 112,800 cuentas personales y sólo se había reintegrado 10.7 millones (Jones 1946, 22). Como se sabe, nunca se llegó a devolver el total del ahorro, la deuda persiste y actualmente se llevan a cabo movilizaciones de ex braceros que exigen el reintegro de sus ahorros, cincuenta años más tarde.

Por otra parte, la burocracia involucrada también tenía sus propios conflictos, discrepancias, filias y fobias. En México, la Secretaría de Relaciones Exteriores negociaba a nivel bilateral, la Secretaría de Gobernación negociaba a nivel interno con las entidades y los gobernadores, mientras la Secretaría de Trabajo y Previsión Social contrataba y llevaba a cabo el proceso. También intervenían otras agencias, como por ejemplo los Ferrocarriles Nacionales que se encargaban del transporte de braceros, la Secretaría de Salud que hacía los exámenes médicos y los militares que controlaban que los contratados tuvieran en orden su cartilla militar. En Estados Unidos, el conflicto se dio entre varias agencias gubernamentales: el Department of Labor (DOL), aliado con los sindicatos que saboteó de diversas maneras 
al Programa Bracero; el Immigration and Naturaliation Service (INS) que paradójicamente se constituyó en su acérrimo defensor; así como el Departamento de Agricultura que apoyaba a los agricultores que requerían de mano de obra (Calavita, 1992). Las diferencias y zancadillas entre dependencias de los gobiernos de ambos países añadieron una serie de problemas suplementarios a la administración del Programa.

4. El problema de los centros de reclutamiento. Otra fuente de diferencias bilaterales y problemas locales fue el lugar donde debería realizarse el reclutamiento. Para México la mejor opción era al interior del país, en las zonas de concentración de la población migrante y no en la frontera, como proponían los norteamericanos y presionaban los empleadores, para ahorrarse los costos del transporte. México ya había experimentado la contratación fronteriza, con las casas de enganche, lo que había sido funesto. Por otra parte, la contratación fronteriza alentaría la migración indocumentada y fomentaría la emigración de la escasa población que vivía en la franja. El reclutamiento pasó del Distrito Federal a las ciudades de Irapuato y Tlaquepaque, luego a Zacatecas, Chihuahua, Tampico y Aguascalientes; también hubo reclutamiento en Hermosillo, Chihuahua y Monterrey, finalmente, en Empalme, Sonora. En los últimos años se accedió a poner un centro de contratación en Mexicali que luego se canceló. El gobierno mexicano perdió, con el tiempo, el control sobre esta situación y fue cediendo ante las presiones de los estadounidenses (Madrazo, 1945; Jones, 1946; Salinas, 1955; Vargas y Campos, 1964).

Como quiera, independientemente del lugar, la confluencia de miles de personas que esperaban ser contratadas ocasionaba múltiples problemas logísticos, que no fueron solucionados de manera adecuada por el gobierno mexicano. Según Pedro de Alba, los centros de contratación eran «uno de los espectáculos más desoladores» que le había tocado presenciar (1954). Se dice que en Empalme, Sonora, sucedía algo similar con la concentración masiva de braceros y la escasez crónica de servicios mínimos

5. Impacto en el mercado de trabajo de ambos países. En quinto lugar, habría que señalar que la contratación masiva de trabajadores temporales afectó necesariamente el mercado de trabajo de ambos países. En México, algunos gobernadores, como el de Guanajuato, se quejaron de la falta de brazos en sus entidades y culpaban al Programa Bracero (Durand, 1994). En Estados Unidos sucedía lo contrario, la queja reiterada de los sindicatos era sobre el excedente de mano de obra barata que desplazaba al trabajador local, bajaba los salarios y, para colmo, eran, en algunos casos, utilizados como esquiroles (Driscoll, 1985; Calavita, 1992).

No obstante, hubo repercusiones serias a largo plazo. En Estados Unidos, se separó de manera definitiva el trabajo agrícola del industrial y dejaron de tener alguna referencia entre ellos. Según McWillians (1954) se suponía que el Programa Bracero no debería impactar negativamente en los salarios, pero en la práctica sí lo hizo, al no haber competencia, ni referencia, entre el trabajo industrial y el agrícola. Una vez que una tarea se convierte en parte fundamental del mercado 
de trabajo migrante es muy difícil revertir este proceso, de ahí la dependencia permanente del sector agrícola americano de la mano de obra mexicana (Galarza, 1964, Durand y Massey, 2003).

En México, por su parte, se dio otra ficción laboral. Se suponía que los braceros aliviaban temporalmente el desempleo, pero en la práctica «La consecuencia mediata (...) que ha tenido el bracerismo, es que por haber enmascarado la sub-ocupación existente ha permitido que cada vez se agrave más...» En efecto, a lo largo de todo el siglo xx, México ha dependido del bracerismo, como medida para aliviar el desempleo y el subempleo, pero como bien dice Vargas y Campos (1964), sólo «enmascaró» el fenómeno y lo agravó, al no buscar soluciones efectivas.

6. El contrato subordina al trabajador. Una crítica recurrente al Programa Bracero ha sido la de la conexión inexorable que existía entre el trabajador y el empleador. El bracero estaba contratado para ir a trabajar a un determinado lugar, rancho o localidad y no podía moverse, incluso si escaseaba el trabajo o, desde su punto de vista, las condiciones eran inadecuadas. Se dice que esta característica le confirió al Programa Bracero un tinte de semi-esclavitud. El trabajador estaba sometido a las condiciones del empleador y dado el carácter temporal y la dispersión de la mano de obra era prácticamente imposible ejercer algún tipo de control oficial, tanto de las autoridades mexicanas como norteamericanas.

Esta limitación no la tiene, paradójicamente, el trabajador indocumentado, que no está sujeto a un contrato, ni a un lugar determinado. Los empleadores utilizan otras formas de sujetarlo y explotarlo, pero finalmente él es libre de vender su fuerza de trabajo en otro sitio. En la actualidad se sigue discutiendo teóricamente este tema, para el caso de los trabajadores temporales al Canadá (Basok, T., 2003). El trabajador migrante contratado no forma parte del proceso de liberación de la mano de obra típico del capitalismo. Al estar sujeto al empleador, sus condiciones se asemejan a las de la época feudal. La relación de dependencia y sumisión se agrava cuando el empleador puede «hacer el favor» de legalizar la situación del trabajador temporal, por medio de su recomendación.

7. Violaciones recurrentes al contrato de trabajo. Finalmente, un tema recurrente fue el incumplimiento de las normas del contrato por parte de los empleadores y los problemas que esta situación acarreaba en las negociaciones bilaterales. Parece ser que las irregularidades más graves se dieron en el cultivo del betabel, así como en el estado de Texas. La práctica del cultivo del betabel dejaba al bracero temporadas libres en las que tenía que buscar otro tipo de trabajo; además, las compañías dejaban pendientes pagos de las últimas semanas, por razones burocráticas, cuando los trabajadores debían salir antes de que llegara el invierno. En el estado de Texas, además de los problemas de discriminación, se tuvieron que modificar de manera imperativa, con coerción por parte del gobierno americano, los mínimos salariales para que se ajustaran con lo acordado en el Programa Bracero y con lo que se pagaba en otros lugares. 
Otro conjunto de problemas recurrentes tenía que ver con los descuentos que aplicaban los empleadores, por distintos rubros: vivienda, alimento, herramientas, préstamos, etc. El trabajo de Ernesto Galarza (1964) demuestra de manera fehaciente cómo los trabajadores eran engañados sistemáticamente a la hora de hacer las cuentas. Este problema se agravaba con el trabajo a destajo, que muchas veces no llegaba a cubrir el mínimo requerido en el convenio, por más que trabajaran intensamente las ocho horas.

Las arbitrariedades en este sentido llegaron a límites increíbles. En 1953, se estipulaba en uno de los artículos del convenio lo siguiente: "Se declara que el patrón no tiene derecho para cargar a la cuenta del trabajador el valor del alambre que se usa para el amarre de zanahorias y otros productos agrícolas, como se acostumbra en algunas regiones de California» (Casarrubias, 1956).

Este es el punto neurálgico de cualquier programa de trabajadores temporales. El gobierno mexicano, en caso de llegar a un acuerdo, tendría que lograr condiciones decorosas para sus trabajadores debido a las presiones de los mismos braceros, los partidos políticos, el congreso y la sociedad. Por su parte, el gobierno estadounidense trataría de lograr las mejores condiciones para los empleadores, es decir pagar lo mínimo posible y trasladar todos los costos posibles a los trabajadores (transporte, vivienda, trámites).

Como quiera, hay dos asuntos que son muy difíciles de solucionar y que forman parte de la idiosincrasia nacional de cada país. En México, el problema de la corrupción es un cáncer que carcome todo el sistema político y el entramado social. Los contratos braceros estuvieron siempre enlodados y manchados por la corrupción de nivel alto, medio y bajo. Lo mismo sucede en la actualidad con las visas $\mathrm{H} 2 \mathrm{~A}$ y $\mathrm{H} 2 \mathrm{~B}$ para trabajadores temporales. Y el problema se agrava porque, además de la corrupción, campea la impunidad. Por su parte, en Estados Unidos, la marcada tendencia a la sobreexplotación de la mano de obra forma parte inexorable del modo de ser del empleador. El espíritu protestante del capitalismo estadounidense se expresa en la imposición de ritmos intensivos de trabajo, control de tiempos y movimientos, traslado de todos los costos posibles al trabajador (transporte, vivienda, seguros), así como la fijación del nivel salarial más bajo posible, hasta donde el bracero aguante.

\section{EL PROGRAMA BRACERO A 50 AÑOS DE DISTANCIA}

La historia de la migración México-Estados Unidos nos ha enseñado que en el mercado de trabajo binacional, si no hay arreglo por la vía formal, el arreglo se da de facto. Es decir, los empleadores contratan los trabajadores indocumentados que sean necesarios y el gobierno se encarga de expulsar los excedentes. La buena marcha de la economía justifica la impunidad de la cual gozan los empresarios y la persecución de los «ilegales» se explica ante la opinión pública, los medios y los electores, por el trabajo de los políticos. 
La vía de facto ha demostrado ser la más viable. Donde paradójicamente todas las partes quedan contentas, aunque nadie lo pueda decir en voz alta. Esta situación de facto se dio cuando se acabaron los convenios. Salvo un número relativamente reducido de braceros que legalizó su situación, los trabajadores mexicanos siguieron cruzando la línea de manera subrepticia y los empleadores los siguieron contratando. A lo largo de 22 años, periodo que comprende la etapa indocumentada, el gobierno mexicano se lavó las manos y aplicó lo que se ha llamado «la política de la no política» (Durand, 2005). Por su parte, el gobierno estadounidense alegaba que tenía la frontera bajo control. Efectivamente, dejaba pasar a aquellos que eran necesarios para levantar las cosechas, la basura, los platos sucios, las sábanas usadas y deportaba, día a día, a los sobrantes.

A los empleadores les interesa un comino si sus trabajadores son indocumentados o «empapelados», lo que le interesa es que sean baratos, eficientes y desechables. Todos contentos y todos felices. Incluidos los trabajadores migrantes mexicanos que, en aquellos tiempos, con 200 dólares o una carrera nocturna cruzaban la frontera y podían ganar algunos dólares, que comparativamente significan mucho.

Cualquier Programa de Trabajadores Temporales va a tener un sinnúmero de complicaciones y de costos. Va a confrontar miles de detractores en todos los bandos, va a generar gastos, corrupción, molestias y enfrentamientos. Pero si consideramos que se trata de un asunto obrero patronal, los conflictos son un elemento cotidiano en la lucha de clases y debemos acostumbrarnos a que sean considerados como algo normal en un mundo globalizado. De este modo los países pobres, con exceso de mano de obra, representan a sus emigrantes y los países ricos a los intereses de sus empresarios.

Cualquier convenio que se firme en el futuro debe tomar en cuenta los aciertos y errores del pasado, concretamente del Programa Bracero y, por parte del país de origen debe partir de las conquistas logradas: negociación bilateral, legalidad, contrato de trabajo, selección de los trabajadores y comunidades involucradas. Por parte del país que acoge: selección de las actividades y los lugares de destino, salarios mínimos establecidos de acuerdo a regiones y pago similar a los trabajadores nativos por las tareas realizadas, seguro médico, seguro de desempleo durante el periodo del contrato, reembolso de los gastos de transporte, vivienda digna, derecho a la organización y a tener representantes. Finalmente, por parte de ambos gobiernos, supervisión y control oficial.

Simplemente, es necesario un programa de esta naturaleza porque el caos existente facilita la sobre-explotación de la mano de obra migrante y fomenta el contrabando de personas. Más aún, el cruce subrepticio de la frontera se ha convertido en una pesadilla para los migrantes, donde se juegan la vida y todos sus ahorros. Además, la frontera ha dejado de ser un problema manejable y ha pasado a ser un asunto de seguridad nacional. La situación se ha polarizado y llevado a ambos países a posiciones de extremo, en sus perspectivas y posiciones. Es 
inaceptable que se siga aceptando la muerte de cientos y miles de migrantes en su intento por pasar la frontera, así como que la frontera del país más rico y poderoso del mundo pueda ser violada con extrema facilidad.

Ante esta situación de extrema urgencia, como sucedió en tiempos de la Primera y la Segunda guerras mundiales, es necesario negociar, es necesario un acuerdo bilateral, porque el flujo histórico y mayoritario de personas hacia Estados Unidos proviene de México y porque, finalmente, ningún otro país tiene las particularidades históricas y de vecindad como el caso mexicano.

\section{BIBLIOGRAFÍA}

Alanís, Fernando (1999), El primer Programa Bracero y el gobierno de México 1917-1918, México, El Colegio de San Luis.

BASOK, Tanya (2003), «Human Rights and Citizenship: The case of Mexican migrant in Canada», Working Paper, núm. 72, 22 de Abril, ccis, University of California-San Diego.

Calavita, Kitty (1992), Inside the State. The Bracero Program, immigration, and the INS, New York, Routledge.

Cardoso, Lawrence (1980), Mexican Emigration to the United States 1897-1931, Tucson, University of Arizona Press.

Carreras, Mercedes (1974), Los Mexicanos que Devolvió la Crisis 1929-1932, México, Secretaría de Relaciones Exteriores.

Craig, Richard B. (1971), The Bracero Program, Austin, University of Texas.

Casarrubias Ocampo, Daniel (1956), El problema del éxodo de braceros en México y sus consecuencias, México D.F., Editorial Injumex.

De Alba, Pedro (1954), Siete artículos sobre el problema de los braceros, México, D.F., Edición del autor.

Driscoll, Bárbara (1985), El Programa de Braceros Ferroviarios, Tijuana, Cuadernos del Cefnomex.

Durand, Jorge (1993), "La cuerda y el enganche. Sistemas de trabajo forzado en el siglo XIX», ponencia presentada en el XII Encuentro sobre la formación del capitalismo en México. La perspectiva regional. Guadalajara, El Colegio de Jalisco, 21-23 de octubre de 1993.

(1994), Más allá de la línea, México, CnCA.

(2005), «De traidores a héroes. Políticas emigratorias en un contexto de asimetría de poder» en Raúl Delgado Wise y Beatrice Knerr (Coordinadores), Contribuciones al análisis de la migración internacional y el desarrollo regional en México, México, Miguel Ángel Porrúa, pp. 15-38.

y Patricia Arias (2005), La vida en el norte. Historia e iconografía de la migración México-Estados Unidos, Guadalajara, El Colegio de San Luis-Universidad de Guadalajara. (2007), Braceros. Las miradas mexicana y norteamericana, Antología 1942-1964, México D.F., Universidad de Zacatecas, Editorial Miguel Ángel Porrúa.

Durand, J. y Douglas S. Massey (2003), Clandestinos. Migración México-Estados Unidos en los albores del siglo XXI, México, Editorial Miguel Ángel Porrúa y Universidad Autónoma de Zacatecas. 
Fernández del Campo, Luis (1946), Los Braceros, México, Secretaría del Trabajo y Previsión Social.

García Tellez, Ignacio (1955), La migración de braceros a los Estados Unidos de Norteamérica, México, Galarza.

GalarZA, E. (1964), Merchants of Labor. The American Bracero History, Santa Bárbara, McNally y Loftin.

Jones, Robert C. (1946), Los braceros mexicanos en los Estados Unidos durante el periodo bélico, Washington, Unión Panamericana.

Madero, Francisco I. (1987), La sucesión presidencial en 1910, México, Editorial Época. Madrazo, Carlos A. (1945), La verdad en el "caso" de los braceros: origen de esta injusticia y nombre de los verdaderos responsables, México, edición del autor.

MarTin, Phillip y Michael S. Teitelbaum (2002), «El espejismo de los trabajadores huésped mexicanos», en Foreign affaire, vol. 2, núm. 1, Primavera. ITAM.

Martínez D., Guillermo (1948), "Los braceros. Experiencias que deben aprovecharse", Revista Mexicana de Sociología, año x, vol. x, núm. 2, pp. 177-196.

Mc BRIDE, J.G. (1963), Vanishing bracero: valley revolution, San Antonio, Texas, The Naylor Company Book Publishers of the Southwest.

McWilliams, Carey (1954), "Los cuervos vuelan hacia el norte», en Problemas agrarios de México, vol. vi, núm. 2, Abril-Junio.

SALINAS, José Lázaro (1955), La emigración de braceros. Visión objetiva de un problema mexicano, México, EDIAPSA.

SAmora, Julian (1971), Los mojados, the wetback story, Notre Dame, E.U., University of Notre Dame.

VARGAS y CAmpos, Gloria (1964), El problema del bracero mexicano, Tesis de Economía, México, D.F., UNAM.

TAYLOR, Paul S. (1930), Mexican Labor un the United States, Chicago and the Calumet Region, Berkeley, University of California Press, vol. viI.

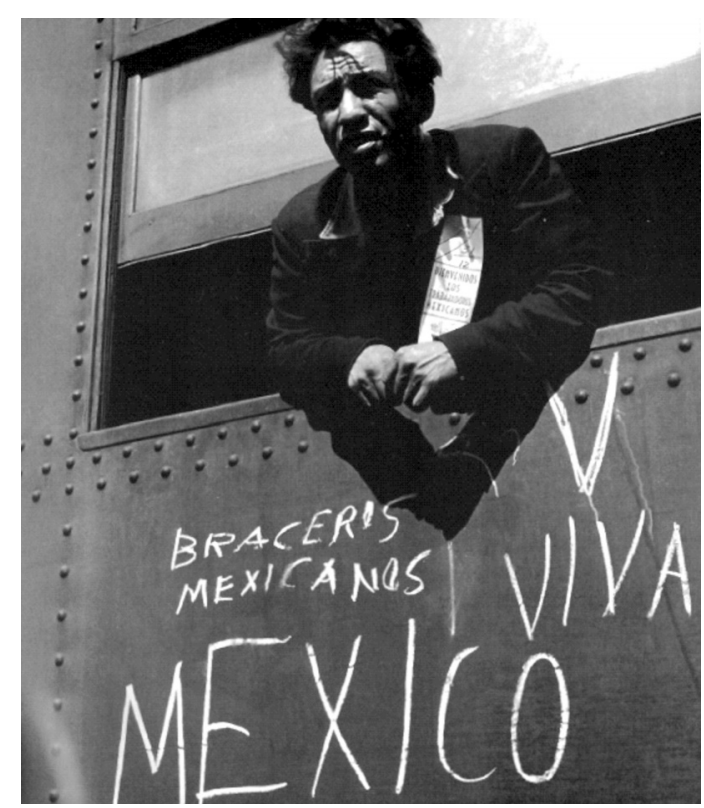


